\title{
Energy management of micro renewable energy source and electric vehicles at home level
}

\author{
Ibán JUNQUERA MARTÍNEZ ${ }^{1}$ @ , Javier GARCÍA-VILLALOBOS ${ }^{\mathbf{1}}$, \\ Inmaculada ZAMORA ${ }^{1}$, Pablo EGUÍA ${ }^{1}$
}

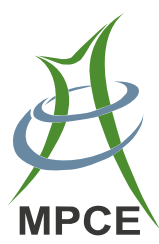

\begin{abstract}
As renewable energy source (RES) tend to be integrated more and more at home and electric vehicles (EVs) take a greater share in the personal automobile market, users see a chance to charge their EVs by microRES. In this context, this paper presents a review about opportunities and challenges needed to be overcome by the EV users to implement a vehicle to home system in their homes, as well as the integration of micro-RES. Several practical scenarios are presented, with different demand profiles, by integrating renewable energy that could be used to charge the EV.
\end{abstract}

Keywords Plug-in electric vehicles (PEV), Vehicle to home (V2H), Micro renewable energy source (micro-RES), Challenges

CrossCheck date: 22 August 2017

Received: 13 September 2015/ Accepted: 22 August 2017 / Published online: 1 November 2017

(C) The Author(s) 2017. This article is an open access publication

$\triangle$ Ibán JUNQUERA MARTÍNEZ

ijunquera001@ikasle.ehu.es

Javier GARCÍA-VILLALOBOS

javier.garciav@ehu.eus

Inmaculada ZAMORA

inmaculada.zamora@ehu.eus

Pablo EGUÍA

pablo.eguia@ehu.eus

1 Department of Electrical Engineering, University of the Basque Country, Leioa, Spain

\section{Introduction}

Electric vehicles (EVs), either battery or hydrogen, do not emit greenhouse gases (GHGs) and reduce oil dependence [1]. Their efficiency is two to three times higher than internal combustion vehicles (ICVs). Moreover, they add value to a network when connected as a distributed storage device for ancillary services. However, a high penetration of EVs can cause overloads, voltage deviations and peak demand on distribution systems. To avoid these problems, the distribution system must be adapted. For example, the evolution of the distribution system towards smart grids brings on the implementation of management systems and charging demand from EV.

On one hand, sales of EVs are continuously growing and are expected to continue increasing in the coming years [2]. In this context, most of the drivers use their vehicles to commute from work to home and buy goods. In general, users spend every day about 75 minutes on average driving, covering an average distance of $40 \mathrm{~km}$ per person [3, 4]. With this data, an EV with $100 \mathrm{~km}$ of autonomy would be the replacement for about $85 \%$ of users, assuming daily load [5]. According to [6], most people use their vehicle from 8:00 to 9:00 a.m. and from 4:00 to 5:00 p.m. This way, most vehicles are at home from 8:00 p.m. to 7:00 a.m. and are available during 11 hours, to be used as a storage system.

Thus, the value added by an EV can be significant. It can be used as a storage device for better integration of renewable energy, as a backup system and may also contribute to reduce the energy bill and to greater efficiency in the use of energy [7]. To this end, technology is being developed to integrate the EVs at home with the least possible impact. 
On the other hand, household energy consumption presents seasonal and daily variations, because of the use of appliances, lighting and heating [8]. With the data of energy consumption of households, it is possible to devise, "bottom-up" energy consumption models based on assumptions or data patterns of activity [9].

In several studies, renewable energy sources (RESs) have been integrated at home with demand management [10, 11]. For example, [12] analyses a photovoltaic (PV) production of $30 \mathrm{~m}^{2}$ for a house of two people, such as that the energy surplus is used to charge the vehicle or feed to the grid. However, the most common problem in the proposed systems is the mismatch between RES production and electricity consumption. Hence, an energy storage system (ESS) can be justified for managing and storing the energy surplus.

In this paper, the possibility of implementing a vehicle to home system $(\mathrm{V} 2 \mathrm{H})$ with real generation data from $\mathrm{PV}$ and wind, as well as consumption data of different users is analysed. User preferences have been taken into account, such as comfort level and consumption priorities in household. The region analysed in the case study has good wind resources but not so good solar resources [13]. Hence, it is necessary to combine both systems for compensation.

The difference from the papers cited before is to demonstrate that micro RES generation could be enough energy for daily consumption of the electric vehicle, for four different scenarios in this area.

\section{Vehicle to home}

It is expected that the installed capacity of RES will increase in a large number of countries. This may cause adverse impacts in the electricity distribution network, due to the intermittency of some RES. In this context, the use of EV could help to solve these problems partially.

Table 1 shows the characteristics of the different interconnected systems with EV. The main feature of these systems is the possibility of a bidirectional energy transfer.

$\mathrm{V} 2 \mathrm{H}$ concept began to have relevance when the need to implement systems to support natural disaster situations, with long time supply outages, was detected in different areas. $\mathrm{V} 2 \mathrm{H}$ systems are designed to be implemented in smart homes, with devices that are able to manage energy. Generally, it consists of a single EV in a home and has a simple and easy configuration. There is no need for major changes in the existing home network to install this system.

The system is able to smooth the daily load profile (DLP) of households, with the exchange of active power and the supply of reactive power to the home. Besides, it can interact with vehicle to building (V2B) and vehicle to grid (V2G) systems. In addition, losses are minimized and the efficiency of RES can be improved. In short, V2H concept aims to harness all the resources and possibilities of the EV. Thus, the energy stored in the EV can be used for better integration of micro renewable resources for feeding household loads.

As shown in Fig. 1, various configurations for renewable generation systems in the home can be considered. There are systems for homes without access to the network (isolated) and with network access (grid connected, zero injection and deferred injection). The deferred injection system incorporates an ESS to store energy from RES. Commercial devices are already available [23].

Therefore, considering the possibilities described a V2H system must be composed at least of: an EV, a bidirectional charger, a set of household loads, distributed generation on a small scale (micro-RES), a smart meter and a home energy management system (HEMS), similar to that shown in Fig. 2 [24]. In addition, intelligent loads, storage systems, i.e., ESS or battery energy storage system (BESS) and even micro-generation with micro gas turbines, i.e., combined heat and power (CHP) can also be included in the system.

Thus all projects that are being carried out are intended to minimize costs to the EV owner, minimize the impact of the EV in the network, support the integration of renewable energy and identify and meet future requirements for the network [25].

The following sections describe the components of a $\mathrm{V} 2 \mathrm{H}$ system and the energy management system.

\subsection{Components of $\mathrm{V} 2 \mathrm{H}$}

The V2H system consists essentially of an EV, a HEMS device, micro-RES generation, ESS, controllable loads and various communication systems.

\subsubsection{Electric vehicle}

Plug-in electric vehicles (PEVs) have been implemented in two technologies, currently on the market, that include an electric motor/generator:

1) Hybrid PEV, which produces electricity from an internal combustion that drives an electric generator.

2) Battery EV that stores electrical energy from the network in an electrochemical battery.

\subsubsection{Smart devices}

Today, increasing attention is being given to intelligent networks and smart homes that can monitor electricity 
Table 1 Different approaches for delivering energy from EV batteries

\begin{tabular}{|c|c|c|c|}
\hline Approach & Advantages & Drawbacks & Pilot projects \\
\hline $\mathrm{V} 2 \mathrm{G}$ & $\begin{array}{l}\text { Operation at large scale } \\
\text { Supply ancillary services } \\
\text { Reactive power support } \\
\text { Improve grid reliability } \\
\text { Electricity market participation } \\
\text { Large scale RES integration }\end{array}$ & $\begin{array}{l}\text { Complex operation } \\
\text { Complex prediction of EV demand } \\
\text { Large number of EVs involved } \\
\text { Communication infrastructure required } \\
\text { User willingness required } \\
\text { Lack of regulatory framework } \\
\text { More industry standards needed } \\
\text { An aggregator is needed } \\
\text { New business models }\end{array}$ & $\begin{array}{l}\text { SMARTV2G [14] } \\
\text { eV2G Project [15] } \\
\text { CGI Project: National V2G School Bus } \\
\text { Demonstration [16] } \\
\text { Grid-on-wheels }[16,17] \\
\text { The Nikola Project }[18]\end{array}$ \\
\hline V2B & $\begin{array}{l}\text { Operation at building level } \\
\text { Ideal for small fleets } \\
\text { Improve local DER (distributed energy } \\
\text { resources) integration } \\
\text { Reduce electricity bill } \\
\text { Provide backup power } \\
\text { Easier EV demand prediction (fleets) } \\
\text { Lower investment needed }\end{array}$ & $\begin{array}{l}\text { User willingness required } \\
\text { Quite complex operation } \\
\text { Poor market integration }\end{array}$ & Nissan Leaf to Building [19] \\
\hline $\mathrm{V} 2 \mathrm{H}$ & $\begin{array}{l}\text { Operation at home level } \\
\text { Normally one EV } \\
\text { Reduce electricity bill } \\
\text { Provide backup power } \\
\text { Easy implementation } \\
\text { Provide energy in isolated houses } \\
\text { Interaction with larger systems } \\
\text { Integration of local DER }\end{array}$ & $\begin{array}{l}\text { Not adequate to residential blocks, only for } \\
\text { single family homes }\end{array}$ & $\begin{array}{l}\text { Leaf to Home [20] } \\
\text { Toyota Smart Homes [21] } \\
\text { Honda Smart Home [22] }\end{array}$ \\
\hline
\end{tabular}

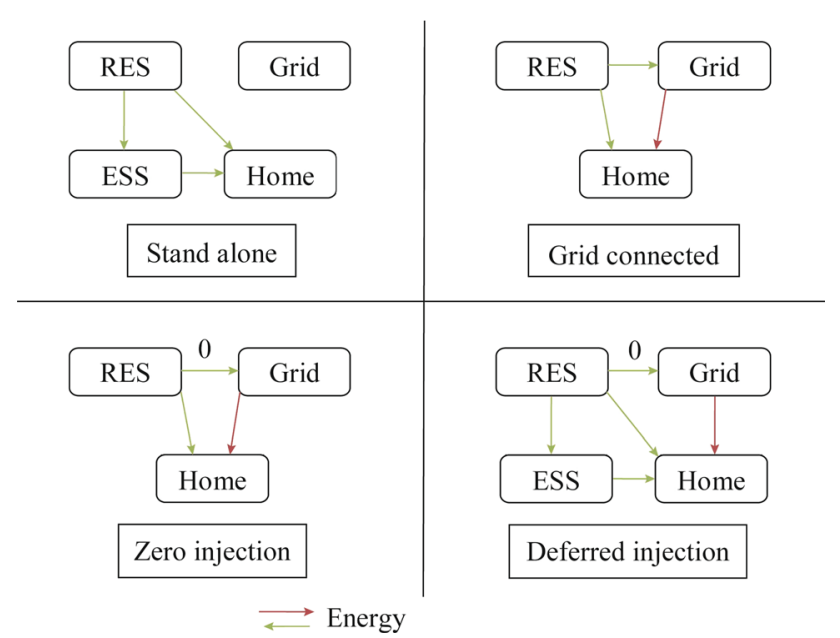

Fig. 1 Auto-consumption systems using RES

usage in real time and take actions to reduce costs. That is, it is focusing on managing demand response (DR), whose key strategy is to allow interaction between smart devices and users. Thus, users have to plan the use of energy (time of use, pricing, priority loads, dynamic pricing, etc.).

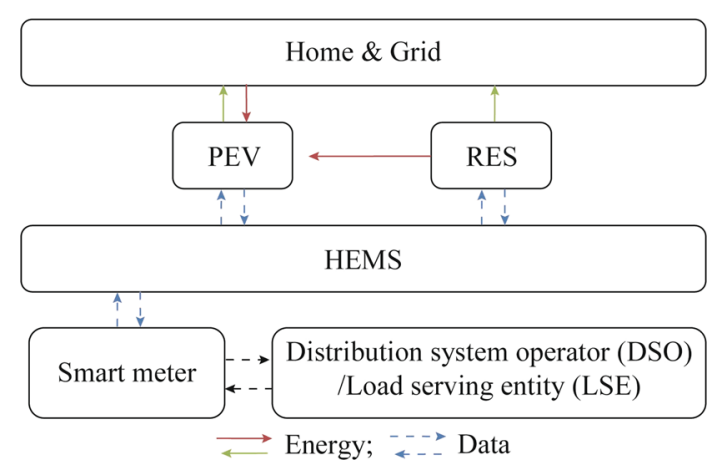

Fig. 2 Vehicle to home scheme

However, while DR is a concept that is sufficiently developed for the industry, it is relatively new for residential users, which consume about $40 \%$ of electricity [10].

In this context, HEMS and smart metering infrastructure, such as smart meters (SM), play an essential role in the effective implementation of DR strategies and $\mathrm{V} 2 \mathrm{H}$ systems for residential areas. Below, the most relevant characteristics of these two systems are presented. 


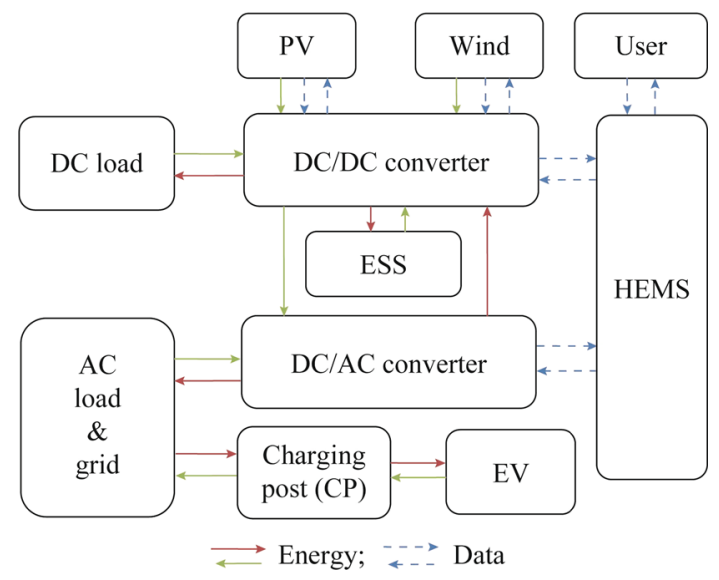

Fig. 3 V2H system scheme

\section{1) HEMS}

The HEMS allows reducing energy consumption of household loads, using intelligent monitoring and control systems. Furthermore, users are able to manage the energy they consume. Figure 3 shows the scheme of the V2H system elements controlled by HEMS, where RES generation, the PEV, storage devices and loads are integrated.

The HEMS, as shown in Fig. 3, consists on a technical platform installed inside the house, with the ability to establish two-way communication with the user, smart devices (SM) and power electronics (converters for RES and ESS). It also integrates home automation functions.

The majority of consumption appliances such as water heater, dishwasher, washing machine, etc., are connected with the HEMS. Thus, there are recorded data of uses and power demanded by the load, plus the load of the EV. At the same time, the HEMS checks the available power generation from RES.

With all these data, the HEMS manages power optimally. In addition, it receives price data from a LSE governed by a distribution company and has the function of demand and load management. The aim is to provide the most economical operation for appliances, along with consideration of user preferences, trying to move demand from peak to off-peak hours. This shift in demand depends on the configuration of the loads, which can be divided into three categories, from the perspective of HEMS: (1)nonprogrammable loads (TV, lighting, etc.); (2) controllable loads (heating, ventilation and air conditioning, refrigerator, EV, etc.); (3) programmable loads (dishwasher, washing machine, etc.).

Demand for non-programmable loads must be supplied continuously, especially to maintain the comfort level of the user. On the other hand, the energy demand of the programmable loads can be modified. In addition, it can be completely displaced from peak to off-peak hours.
Related to the charging of EVs, an example application is the electric vehicles learning static (EVLS) model $[26,27]$, where the integration of RES in the EV charging process is simulated. The results show the differences between uncontrolled charging, smart charging and bidirectional charging. They show that the combination of renewable generation and the integration of EVs help smooth the demand profile.

\section{2) Smart meter}

A smart meter collects electricity usage and related information from customers and delivers data to customers. This advanced metering infrastructure (AMI) differs from traditional automatic meter reading (AMR) because it allows two-way communication [28].

Measurements are diverse and real-time. Thus, it does not mean that users need to have the necessary knowledge to adequately respond to signals from the devices and the network. However, the success of demand control is based on a complete automation, using smart devices.

\subsubsection{Micro-RES}

Interest in energy generation from alternative sources has led to decentralized energy production through microgrids. Besides reducing transmission losses, the microgeneration offers a way for the integration of renewable energy into the grid. Thus, micro-RES, based on photovoltaic and wind power, are becoming a key source of energy [29]. Due to the fact that residential sector is one of the largest electricity consumers, small-scale RES have a promising future in this market segment.

In this context, some studies [27,30] show that the use of micro-RES to charge the EV may be feasible in the short term, and thus reduce electricity demand at home, also reducing the need for costly upgrades of the network. However, these studies also reveal that, in the long term, updates will be necessary in the system. That is, the energy production from renewable sources, without smart charge, will not be able to meet the increased demand due to the EV.

Considering different renewable distributed generation systems, solar panels are the most viable option when installing RES at home. Different methodologies have been considered for integrating PV and the plug-in hybrid electric vehicle (PHEV) at home [30], to determine the optimal size of a PV system for a $65 \mathrm{~km} /$ day range [31], to show household loads [32], to calculate solar-powered for a net zero-energy [33], to determinate economic reliability of charging PHEV with PV [34], to remark PV and PHEV impact in voltage and network losses [35], etc. 


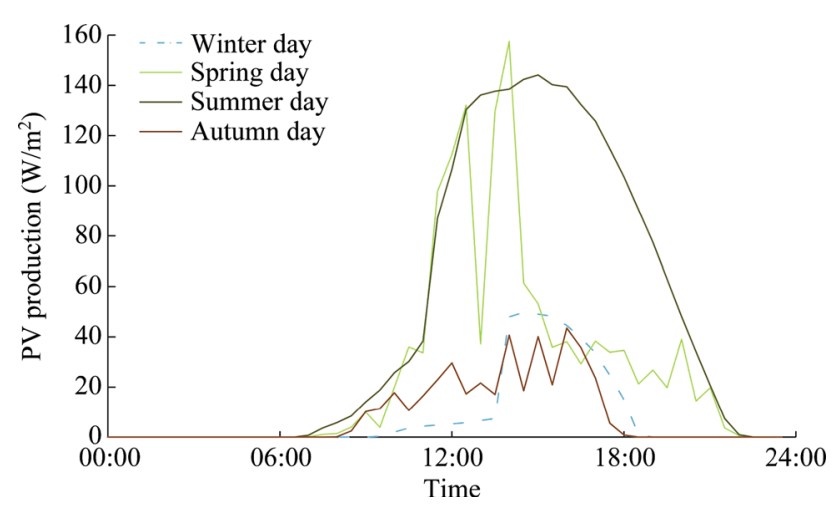

Fig. 4 Distribution of PV production

Additionally, according to [36], a V2H system with rooftop PV could provide backup energy at home between 19 and 600 hours, depending on the season of the year.

For example, Fig. 4 presents the available PV power per unit area in the case study presented in Section 4 [13]. Photovoltaic production has a predictable and progressive profile. However, the largest energy production peak does not match with the peak demand at home, between 20:00 and 23:00.

As for domestic wind generators, the optimal system is connected to a storage system, to satisfy the home demand. In addition, the knowledge of the correct sizing of the equipment and the choice of the most suited wind turbine, based on nominal wind speeds, is needed.

The profile of wind speed evidences a changing trend in the different seasons. Fig. 5 shows the data for the area considered in the case study presented in Section 4 of this paper [13]. During the winter months, the probability of generation is higher for wind than for PV, being February and March the most suitable time for this energy generation. From the data obtained, it can be concluded that in the range of $2 \sim 12 \mathrm{~m} / \mathrm{s}$, with a sustained wind speed, the power available per turbine would be under $11 \mathrm{~kW}$ [37].

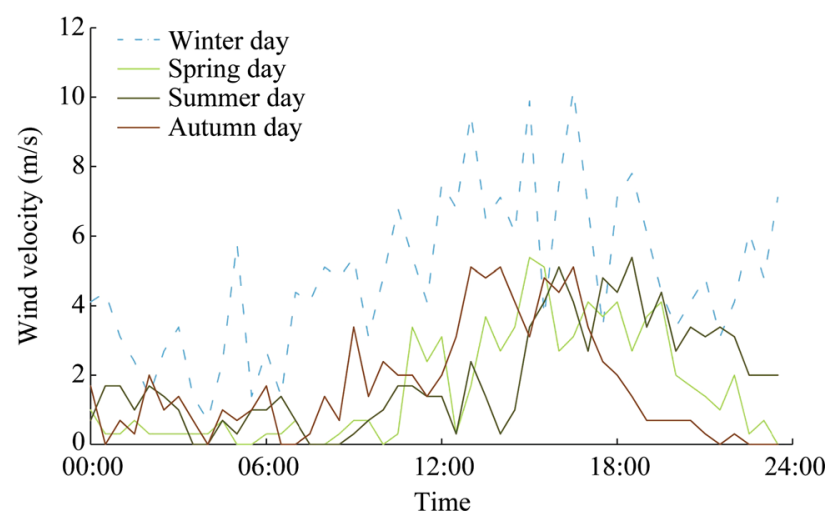

Fig. 5 Wind speed profile

\subsubsection{Energy storage system}

The use of the energy stored in the EV battery, to smooth the electricity demand during peak hours through $\mathrm{V} 2 \mathrm{H}$, can be a potential application of DR strategies. Apart from the battery that integrates the EV, there are ESSs that facilitate energy management when the EV is not connected.

Some papers analyse DR strategies for operating the ESS optimally, in smart homes [10]. Thus, [38] takes into account the expected price for the user.

Reference [39] focuses on the strategy of a HEMS for a smart home, including PV, EV and ESS. The charge is smart, based on the use of both storage systems, EV and ESS. In [40-43], one DR strategy is presented with HEMS, considering peak power limit in a smart home, including intelligent appliances and an EV. In addition, studies have been made taking into account dynamic prices, use of appliances, external conditions and comfort requirements [44-47].

These studies have contributed to the implementation of smart grid concepts at home. However, many of the options published have failed to significantly reduce the energy demand through the contribution of distributed renewable energy. That is, the $\mathrm{V} 2 \mathrm{H}$ option is feasible to reduce peak demand periods provided that is accompanied by an ESS, along with different DR strategies in the HEMS. The most significant reduction, in terms of costs, occurs when RES and ESS systems are combined, resulting in a cost reduction up to $35 \%$ [10].

Moreover, ESS sizing depends on the installed RES power capacity. Increased capacity of both systems, RES and ESS, provides a reduction in the total daily cost of electricity. This option is due to increased flexibility for HEMS to manage the flow of energy. However, installing larger systems should be evaluated in detail, with pros and cons, considering the payback of the facility, reduced costs, etc.

For example, Tesla Motors has already presented a battery in the market, for residential use, in support of renewable generation systems. This will allow the supply of households with less dependence on the grid and the integration of solar and wind energy [48].

\subsubsection{Communication systems}

Communication systems are installed between HEMS management devices and appliances, as well as with the EV charger in Table 2. In addition, the power electronic based devices of RES systems and other connection devices to the network have to be communicated by cable or wirelessly, with the HEMS. 
Table 2 Cable communication systems

\begin{tabular}{llll}
\hline $\begin{array}{l}\text { Communication } \\
\text { protocol }\end{array}$ & Range & $\begin{array}{l}\text { Band width } \\
(\text { Mbit/s })\end{array}$ & Standard \\
\hline DSL & $>2 \mathrm{~km}$ & 8 & ANSI T1.413 \\
RS-485 & $<1.2 \mathrm{~km}$ & 0.1 & - \\
& $<10 \mathrm{~m}$ & 34 & \\
Ethernet & $<100 \mathrm{~m}<10 \mathrm{~km}$ & 10 & IEEE 802.3 \\
& & $10 \mathrm{e} 3$ & \\
CAN-bus & $<40 \mathrm{~m}$ & 1 & ISO 11898-1 \\
& $<100 \mathrm{~m}$ & 0.125 & \\
PLC & $>1 \mathrm{~km}$ & 0.5 & - \\
& $<100 \mathrm{~m}$ & 125 & \\
\hline
\end{tabular}

According to the communication distance, ZigBee could be use from home to the nearest transformer in Table 3 . Data considered are the application of DR, the price of electricity, prognosis, etc. However, different wireless communication systems make available, in real time, the data necessary for optimal management by the HEMS. Thus, depending on the application and the distance between the devices, different protocols can be used.

Communication in systems such as V2G already have a standard [49]. Moreover, [50] presents a hybrid remote control between V2H/V2G, controlled and monitored via the Internet, able to respond to demand signals sent from the LSE.

\subsection{Energy management}

The user is the final responsible for managing the EV. To this end, the demand forecast using historical data may be useful for predicting the behaviour of the network and acting accordingly to a higher profit. Therefore, with the user preferences defined, the LSE (or user group) can take decisions about the management of HEMS at any time, according to the market and the expected RES generation. In addition, the user can modify preferences, agreed with some limit benchmarks for electric grid stability.

If the HEMS has communications, the user preference and demand data, as well as electricity prices are updated in real time. However, in facilities where no communication systems exist, it would also be possible to implement a V2H system. Demand and user preferences are two aspects that can be changed manually in the HEMS device. Table 4 shows different options of working, for a HEMS within a V2H system.

Moreover, active energy management at home can be done through an application for mobile devices, in which the users can have their own credentials. From this application, the user can view and modify the parameters that
Table 3 Wireless communication systems

\begin{tabular}{llll}
\hline $\begin{array}{l}\text { Communication } \\
\text { protocol }\end{array}$ & Range & $\begin{array}{l}\text { Band width } \\
(\text { Mbit/s })\end{array}$ & Standard \\
\hline Wi-Fi & $50-250 \mathrm{~m}$ & 54 & IEEE 802.11 \\
GPRS & $<2 \mathrm{~km}$ & $0.056-0.114$ & GSM Standard \\
Bluetooth & $<100 \mathrm{~m}$ & 2.1 & - \\
RFID & $<0.1 \mathrm{~m}$ & $0.106-0.848$ & IEC 14443 \\
& & & IEC 15693 \\
NFC & $<0.2 \mathrm{~m}$ & 0.424 & IEC 14443 \\
ZigBee & $<10$ & 0.02 & EU EN300-220 \\
& $75 \mathrm{~m}$ & 0.250 & \\
Z-Wave & $30 \mathrm{~m}$ & $0.0096-0.04$ & EU EN300-220 \\
Wavenis & $<100 \mathrm{~m}$ & $0.0048-0.1$ & EU EN300-220 \\
\hline
\end{tabular}

Table 4 Operating modes

\begin{tabular}{lll}
\hline Modes & RES ON & RES OFF \\
\hline PEV charged & RES to home (R2H) & V2H \\
PEV & RES to vehicle/home & Grid to vehicle/home \\
discharged & (R2V/H) & $(\mathrm{G} 2 \mathrm{~V} / \mathrm{H})^{*}$ \\
\hline
\end{tabular}

Note: * Off-grid zones or "Stand Alone" it needs storages (ESS)

the HEMS manages (state of charge (SOC), $t_{\mathrm{on}}, t_{\mathrm{off}}$, loads at home, etc), by preferences that come instantly to the LSE. The LSE processes market data and available RES generation and returns data signals of electricity prices to HEMS, to carry out the management of energy optimally.

Figure 6 shows the flow of information between HEMS and LSE. The LSE operates on the basis of different pricing schemes, time of use (TOU), peak prices and prices in real time, etc. [51]. The main data arriving and departing to HEMS are:

1) PEV: SOC, $t_{\mathrm{on}}, t_{\text {off }}$ (routine use).

2) RES: generation forecast $\mathrm{kWh}$.

\section{Opportunities and challenges for users}

Power generation systems from renewable sources, installed at home, are small scale. Adding an EV and HEMS can improve the efficiency of these systems. From this point of view, there are several opportunities and challenges for the user of the EV, with own $\mathrm{V} 2 \mathrm{H}$ or residential generation systems. Some opportunities and challenges that still remain to be solved are pointed out.

1) Opportunities

Energy from RES generation may be sufficient during $70 / 80 \%$ of the year, to charge the EV, corresponding to a 


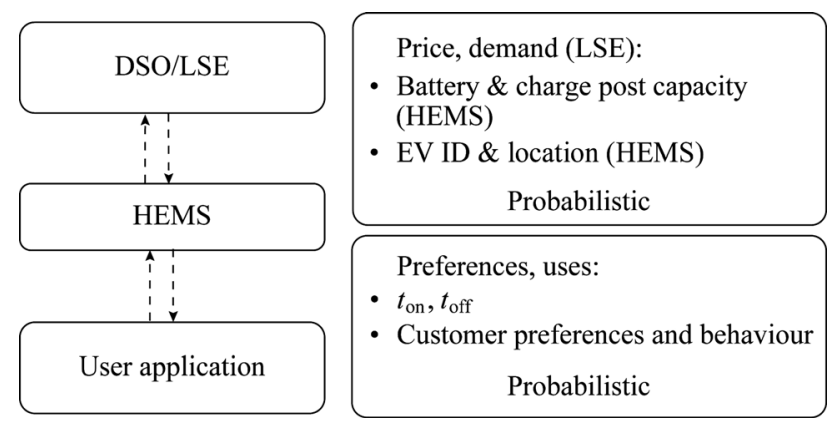

Fig. 6 Information transmitted to HEMS

daily demand for one-way journey $(>2.4 \mathrm{kWh})$. It is assumed that the user's preferences and the consumer behaviour are known accurately.

The period of maximum generation (9:00-15:00) does not match with the peak demand (18:00-24:00) in the case of photovoltaic energy [52]. However, combining PV and wind systems leads to better integration of energy. In addition, an ESS can be installed.

The EV increases the maximum energy demand of the house but can be offset by an ESS. With prices in real time, the ESS also helps to reduce the cost of energy. In addition, researchers are exploring the possibility of reusing the EV used batteries for energy storage in the network and homes. So, the EV batteries could have a second life [53].

\section{2) Challenges}

Range anxiety of available kilometres is crucial for the implementation of systems as $\mathrm{V} 2 \mathrm{H}$. To relieve this range anxiety, user has to be informed of the power management options that are available. Through enabling applications to take control of HEMS, the user will be informed about all parameters of the V2H system in real time. Some studies show that the availability of public charge greatly decreases range anxiety and increases the use of EVs [54].

The infrastructure of the electrical distributor has to be standardized. The distributor has to ensure safely the integration of micro-generation systems. Moreover, charging of EVs involves a number of requirements, such as ground electrode at home, existence of a neutral wire in the network and load studies of the transformer close to the V2H system.

Need for knowledge by the user. The energy management through smart devices assumes that the user has the basic skills to carry it out. For example, communications should serve to better optimization of energy management. In fact, the user is who can parameterize the data concerning the EV as SOC, $t_{\mathrm{on}}, t_{\mathrm{off}}$, plus programming the appliances.

\section{Case study}

In the case study presented, the aim is to minimize the energy consumption from the grid by integrating RES and to analyse the final impact related to the charging and discharging of EV. Limitations considered are:

1) The EV battery must be fully charged at morning.

2) The EV battery cannot be charged from the grid during peak hours.

Four particular scenarios of demand (family home, individual home, country house and Farm house) are presented below. Table 5 shows the main features of each user and results are shown in Figs. 7, 8, 9, 10.

Wind data and solar radiation have been measured at the north of the state of Burgos (Spain), where single-family homes exist. So, it is possible to incorporate power generation with PV and Wind turbines. Data have been obtained by a weather station Alecto WS-5000.

Renewable generation considered for the four scenarios is the same: $10 \mathrm{~m}^{2}$ of solar panels and a wind turbine of 1 $\mathrm{kW}$ rated power (1.5 $\mathrm{kW}$ peak power). The payback for a system as described is about 10 years [34]. A $1 \mathrm{~kW}$ wind generator has been chosen for constructive reasons, dimensioning, generation capacity and performance at speeds between $2-10 \mathrm{~m} / \mathrm{s}$. PV panels are dimensioned by the peak power recorded by the weather-station, which corresponds to $240 \mathrm{~W} / \mathrm{m}^{2}$. Then, for the available area, the peak power is $3 \mathrm{~kW}$.

On the other hand, the use of an ESS for energy management is determined at the end of the case study, once the energy results are obtained. Energy produced by PV and micro wind does not match with periods of peak power demand at home. Thus, adding an ESS system ensures greater integration of the available RES. This way, the HEMS has to manage the energy available in the EV and the ESS.

The EV is not available at home during the working time (typically 8:00-19:00), when the ESS stores the energy generated by the micro-RES, for later consumption.

Table 5 User features

\begin{tabular}{|c|c|c|c|}
\hline User & $\begin{array}{l}\text { Number } \\
\text { of people }\end{array}$ & $\begin{array}{l}\text { Power } \\
(\mathrm{kW})\end{array}$ & Principal use \\
\hline Home 1 & 3 & 3.45 & $\begin{array}{l}\text { Continuous use } \\
\text { Appliances, lighting and pumps }\end{array}$ \\
\hline Home 2 & 1 & 3.45 & $\begin{array}{l}\text { Continuous use } \\
\text { Appliances and lighting }\end{array}$ \\
\hline Home 3 & 2 & 3.3 & $\begin{array}{l}\text { Weekend use } \\
\text { Appliances, lighting and pumps }\end{array}$ \\
\hline Farm & - & 5.75 & $\begin{array}{l}\text { Weekday use } \\
\text { Compressor, cereal mill, welder, } \\
\text { lighting and electric tools }\end{array}$ \\
\hline
\end{tabular}




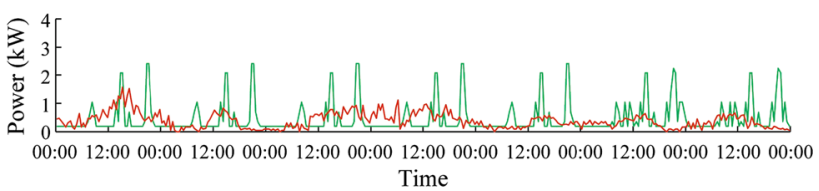

(a) Winter

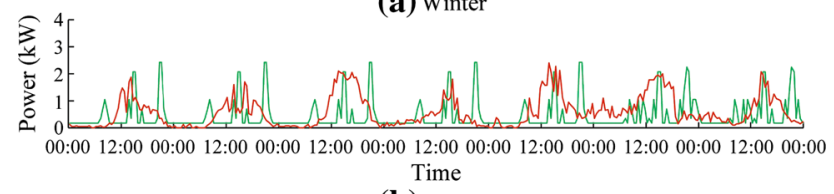

(b) Spring

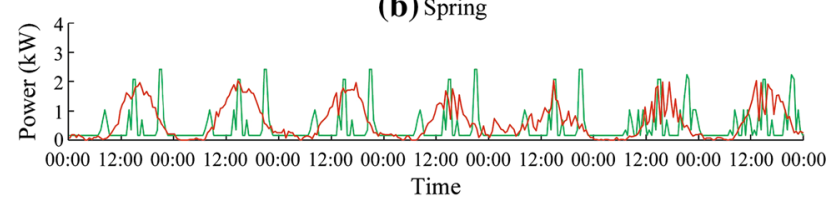

(c) Summer

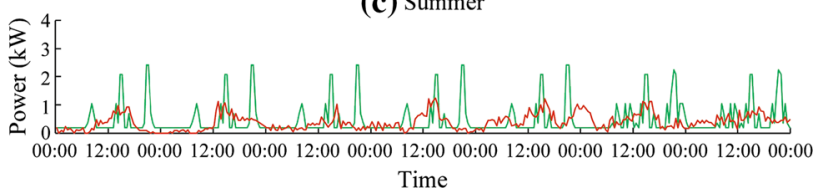

(d) Autumn

- Demand; - Micro-RES

Fig. 7 Demand and RES generation for Home 1

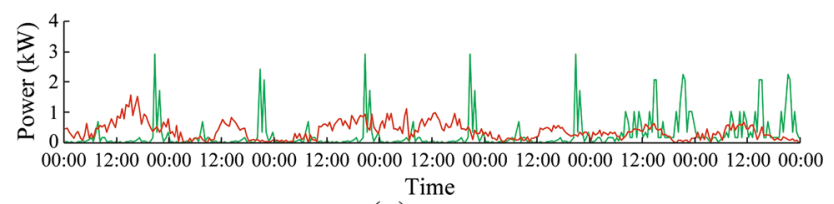

(a) Winter

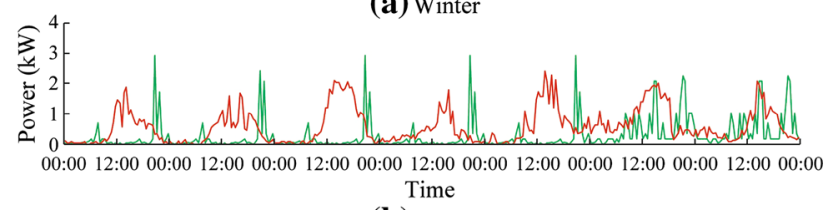

(b) Spring

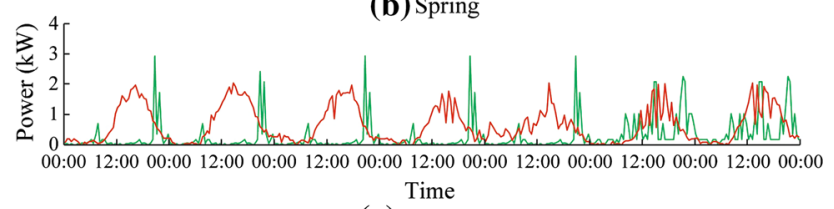

(c) Summer

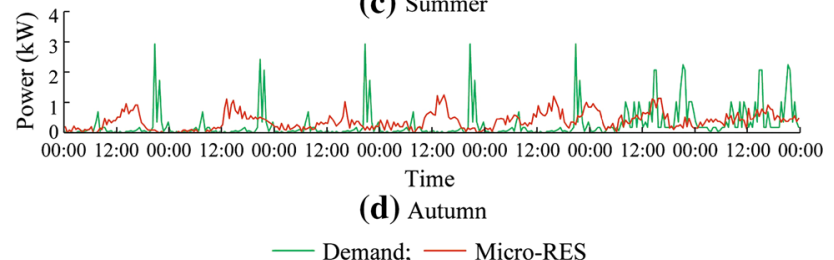

Fig. 8 Demand and RES generation for Home 2

Normally, when the workday ends, the charging of EV is done directly from the energy stored in the ESS or the micro-RES generation available at that moment.
The daily power demand is more predictable in working days than during the weekend or holidays. In addition, periods of increased energy consumption usually correspond with extreme temperatures, like very cold and heat periods.

\subsection{Home 1}

Figure 7 shows the wind and PV generation, along with the demand profile of scenario Home 1, in weekly periods, for the four seasons of the year. In the summer season photovoltaic dominates the generation. However, during the winter season the energy from RES comes mainly from micro-wind.

In this case, the weekly demand profile presents periods when the power demanded is greater than that generated by RES. Furthermore, in terms of energy, it can be seen that demand is greater than generation in autumn days and, to a lesser extent, in winter. In cases where demand is greater than generation, the EV can provide energy to the home by V2H concept.

\subsection{Home 2}

Figure 8 shows the micro-RES generation with the demand profile of scenario Home 2, in weekly periods, for the four seasons of the year. In this case, the energy demand is for a single person, so power peaks are more localized.

During the weekend the distribution is scattered and less predictive. However, the amount of micro-RES generation in all periods of the year is greater than the demand. This way, the user will have enough energy at any time. This energy surplus can be used for charging the EV.

\subsection{Home 3}

Figure 9 shows the energy demand and micro-RES generation, in scenario Home 3 , in weekly periods, for the four seasons of the year. The energy demand during weekdays is scarce, only peak power appliances such as a refrigerator or freezer, which start occasionally or eventually. It is because this property is used exclusively for weekends. That is, the demand is concentrated in the weekend-days. Thus, during the week enough energy surplus is produced to meet the demand of the weekend. In this case, it would be able to export energy to the grid for better use and integration of micro-RES resources.

\subsection{Farm house}

Figure 10 shows the micro-RES generation with the energy demand profile for Farm house scenario, in weekly 


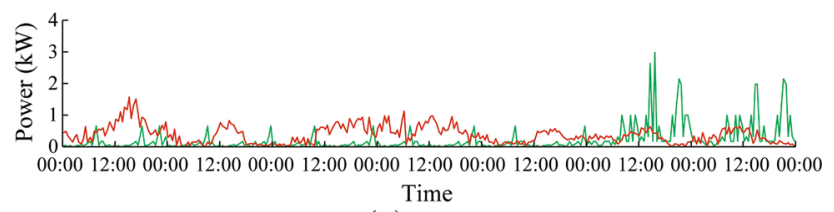

(a) Winter
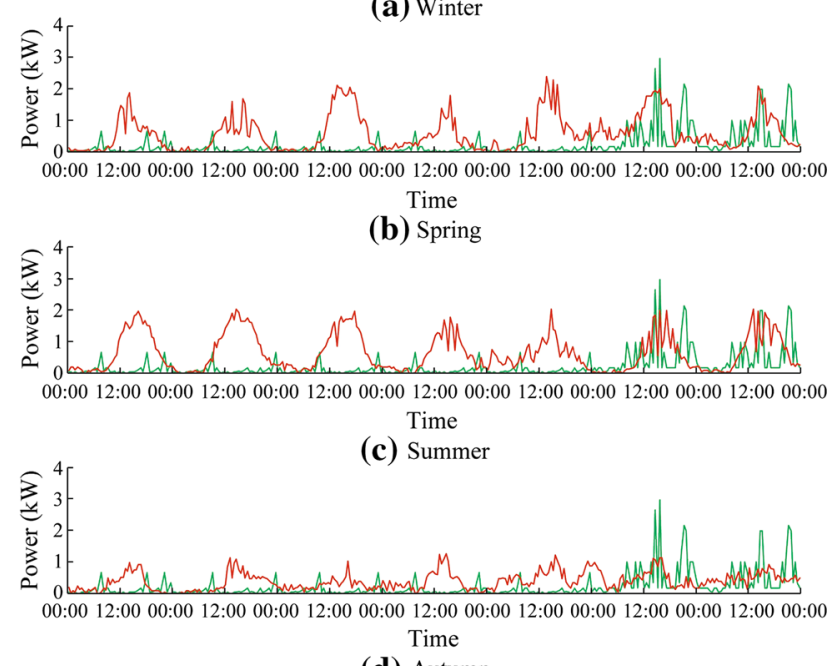

(d) Autumn

— Demand; — Micro-RES

Fig. 9 Demand and RES generation for Home 3

periods, for the four seasons of the year. The profile of the farm house presents higher peaks of power, ranging from 1 to $4 \mathrm{~kW}$.

The energy is mostly demanded during weekdays. As can be seen, the power demanded in no case is covered with the micro-RES generation installed. However, the energy from renewable sources is greater than the energy demanded, for approximately $70 \%$ of the year (four months a year is not enough).

\subsection{Comparative analysis}

For the four scenarios analysed, a model that takes into account stochastic demand values, use of the EV and use of home appliances, has been applied. RES production is given by the PV area and the wind speed.

The characteristics of energy consumption are analysed in detailed in Figs. 11, 12, 13, 14. Positive values (red) show the power generation of RES system and negative values (blue) show consumption of energy by the user. The energy balance (green colour) can be positive or negative:

1) Home 1: It is a 3 people home, with normal habits of home energy use. Given the demand profile in this case, during the autumn and winter months, the RES generation is not enough to meet the demand. The average energy demand is $8.7 \mathrm{kWh} /$ day. The excess energy in the spring and summer is stored in the ESS

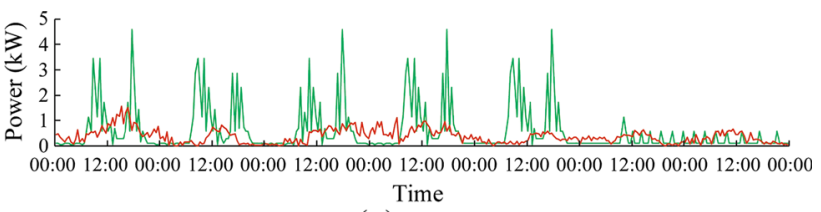

(a) Winter

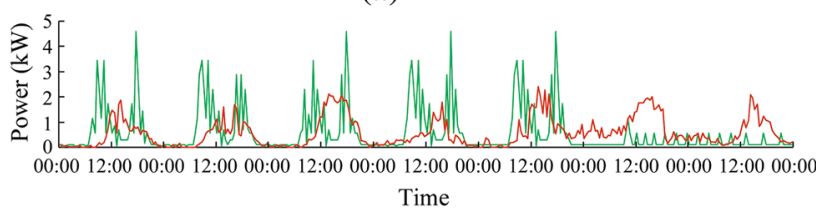

(b) Spring

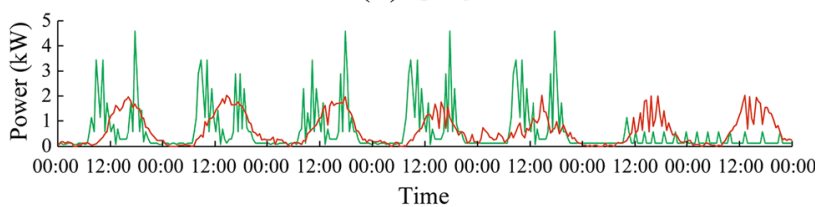

(c) Summer

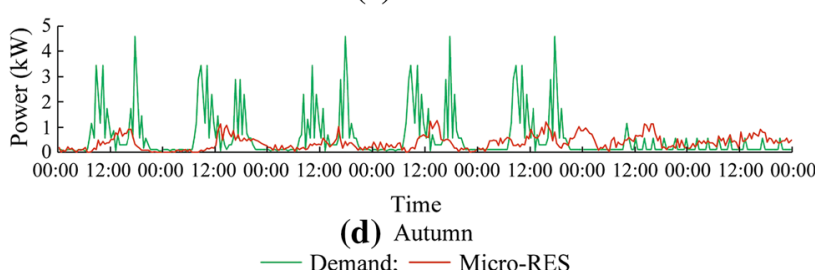

Fig. 10 Demand and RES generation for Farm house

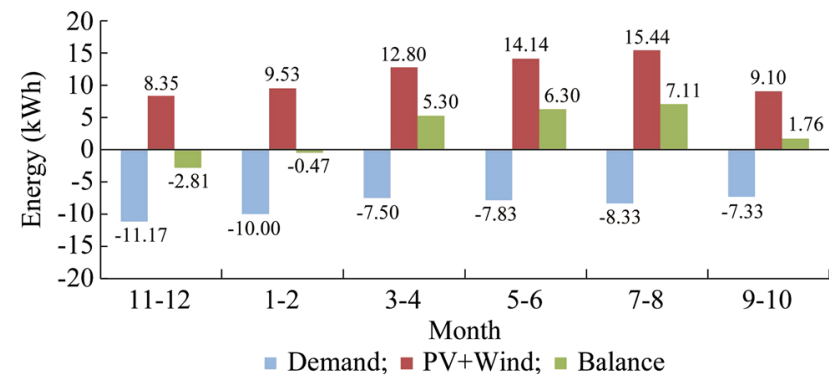

Fig. 11 Energy balance (Home 1)

to charge the EV or consumed in household appliances. The daily average net balance is $2.9 \mathrm{kWh} /$ day in Fig. 11.

2) Home 2: One-person home. The daily average net balance is positive and corresponds to $9.5 \mathrm{kWh} /$ day. It is because of the demand profile of the user and the configuration of the renewable generation. The daily average net balance demand is $2.1 \mathrm{kWh} /$ day in Fig. 12 .

3) Home 3: Country house with two people. The daily average demand is $4.7 \mathrm{kWh} /$ day and the daily net balance is $6.9 \mathrm{kWh} /$ day in Fig. 13.

4) Farm house with industrial appliances. The daily average energy demand is $438 \mathrm{kWh}$. The micro-RES 


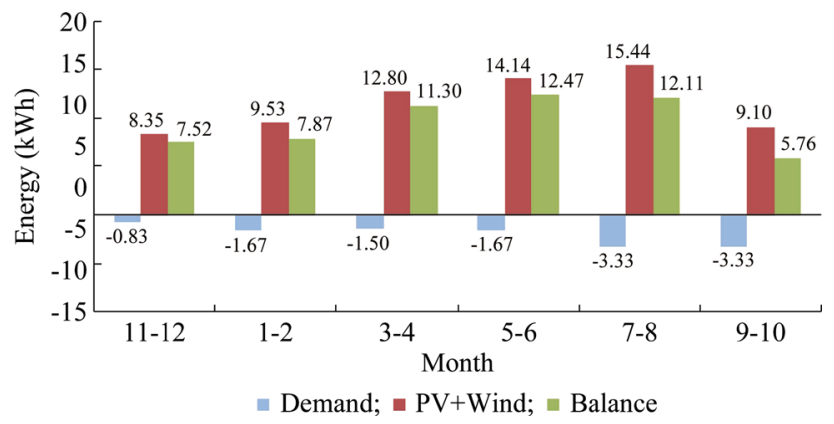

Fig. 12 Energy balance (Home 2)

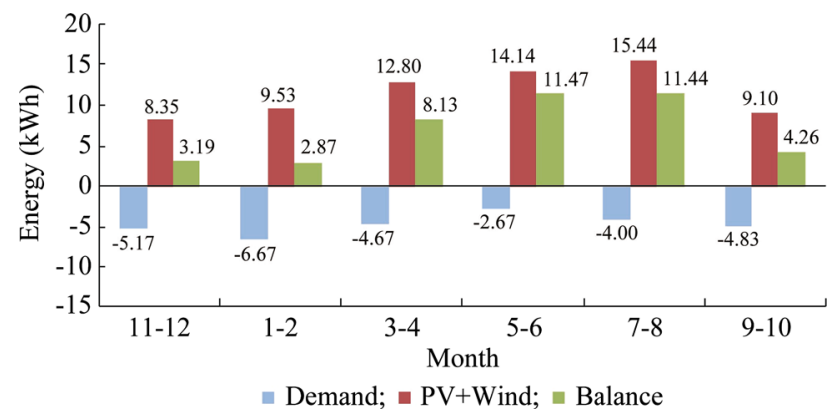

Fig. 13 Energy balance (Home 3)

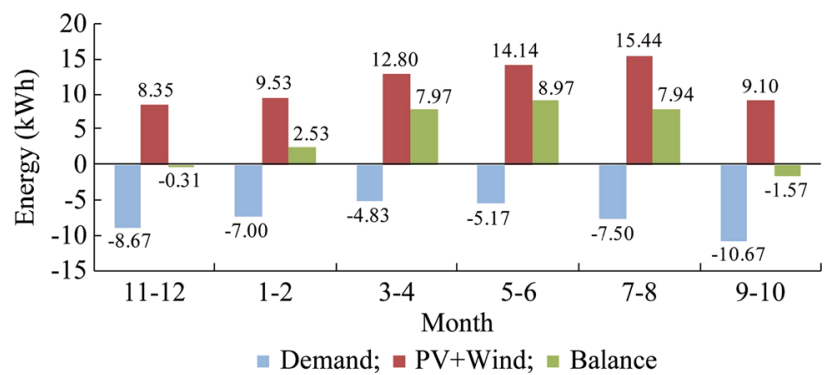

Fig. 14 Energy balance (Farm house)

generation supports the consumption and means a positive net balance of $4.3 \mathrm{kWh} /$ day in Fig. 14 .

As shown in Table 6, the worst case (Home 1) allows having enough energy to travel $12.3 \mathrm{~km}$ a day (going to work $2.4 \mathrm{kWh} /$ day with energy consumption of $20 \mathrm{kWh} /$ $100 \mathrm{~km})$. This range is useful if there is a charger available in the destination. To cover the total daily demand, about 8 $\mathrm{kWh}$ would be needed, corresponding to a range of $40 \mathrm{~km}$ in most EVs (electrical utility).

Considering the results obtained, ESS sizing has to be performed according to the surplus production of RES. According to the studied energy balances, the average power over the RES generation of all scenarios is about 5
Table 6 Values of energy available for charging PEV

\begin{tabular}{llll}
\hline Household & $\begin{array}{l}\text { Capacity }(\mathrm{kWh} / \\
\text { week })\end{array}$ & $\begin{array}{l}\mathrm{EV}(\mathrm{kWh} / \\
100 \mathrm{~km})\end{array}$ & $\begin{array}{l}\text { Distance } \\
(\mathrm{km} / \text { day })\end{array}$ \\
\hline Home 1 & 17.2 & $10-20[55-58]$ & 12.3 \\
Home 2 & 57.0 & & 40.7 \\
Home 3 & 41.4 & & 29.5 \\
Farm & 25.5 & & 18.2 \\
\hline
\end{tabular}

$\mathrm{kWh}(12.1 \mathrm{kWh}$ is the maximum and $-2.8 \mathrm{kWh}$ the minimum). Thus, the capacity of the ESS should be between 8 to $12 \mathrm{kWh}$, to ensure optimal use of the renewable resources. In the worst case, with backup of the EV battery, this energy would be enough to feed the household scenarios for at least one day. Although the range for an EV is reduced, the capacity of on-board batteries provides enough energy for household electric consumption management [11].

\section{Conclusion}

Currently, solutions given for charging electric vehicles allow offering a wide coverage at home, using low voltage systems. Additionally, there are many appliances that demand electric energy and the grid have to support them. For one hand, short term needs could be covered by residential RES. On the other hand, within a period of long time, perhaps demand cannot be met only with the current RES technology. Improvement in RES systems and network will be needed.

A suitable combination of systems based on renewable energy, storage devices, smart devices and EVs will allow to obtain significant benefits in terms of operating costs, environmental impact (by reducing oil consumption) and reliance on the power grid.

The four scenarios in this research work shows that the renewable resource available and the EV could supply enough energy to the users demand in all seasons of the year.

Additionally, smart technologies that will emerge in the future will provide more flexibility and economic possibilities. This way, the end user can participate in the energy market, provided that the regulatory framework of the electricity market keeps up with technological advances. Installation costs should also be considered in order to assess the real benefits of this type of investment.

Finally, V2H systems will support to the achievement of the overall reduction of GHGs, use of fossil fuels and meeting the objectives of sustainability, with special attention to help further integration of RES in homes and the grid. 
Acknowledgements This work was supported by a grant of the Basque Government (No. PRE-2013-2-392) and the University of the Basque Country -UPV/EHU (No. PES-15).

Open Access This article is distributed under the terms of the Creative Commons Attribution 4.0 International License (http:// creativecommons.org/licenses/by/4.0/), which permits unrestricted use, distribution, and reproduction in any medium, provided you give appropriate credit to the original author(s) and the source, provide a link to the Creative Commons license, and indicate if changes were made.

\section{References}

[1] Kudoh Y, Motose R, Tahara K et al (2013) A potential CO2 reduction of vehicle to home system from life cycle perspective. In: Proceedings of 2013 World Electric Vehicle Symposium and Exhibition (EVS27), Barcelona, Spain, 17-20 Nov 2013, 10 pp

[2] Trigg T, Telleen P, Boyd R et al (2013) Global EV outlook: understanding the electric vehicle landscape to 2020. International Energy Agency

[3] Krumm J (2012) How people use their vehicles: statistics from the 2009 national household travel survey. In: Proceedings of SAE 2012 World Congress \& Exhibition, 16 April 2012, 12 pp

[4] Streit T, Chlond B, Vortisch P et al (2013) Deutsches mobilitätspanel (MOP)—wissenschaftliche begleitung und auswertungen bericht 2012/2013: alltagsmobilität und fahrleistungen. KIT, 1-138 pp

[5] Kempton W, Tomić J (2005) Vehicle-to-grid power implementation: from stabilizing the grid to supporting large-scale renewable energy. J Power Sources 144(1):280-294

[6] Clement-Nyns K, Haesen E, Driesen J (2010) The impact of charging plug-in hybrid electric vehicles on a residential distribution grid. IEEE Trans Power Syst 25(1):371-380

[7] Tuttle DP, Fares RL, Baldick R et al (2013) Plug-in vehicle to home (V2H) duration and power output capability. In: Proceedings of 2013 IEEE Transportation Electrification Conference and Expo, Detroit, USA, 16-19 June 2013, 7 pp

[8] Munkhammar J, Widén J, Rydén J et al (2015) On a probability distribution model combining household power consumption, electric vehicle home-charging and photovoltaic power production. Appl Energy 142:135-143

[9] Richardson I, Thomson M, Infield D et al (2010) Domestic electricity use: a high-resolution energy demand model. Energy Build 42(10):1878-1887

[10] Erdinc O (2014) Economic impacts of small-scale own generating and storage units, and electric vehicles under different demand response strategies for smart households. Appl Energy 126:142-150

[11] Yoshimi K, Osawa M, Yamashita D et al (2012) Practical storage and utilization of household photovoltaic energy by electric vehicle battery. In: Proceedings of 2012 IEEE PES Innov Smart Grid Technol (ISGT), Washington, USA, 16-20 Jan 2012, 8pp

[12] Munkhammar J, Bishop JDK, Sarralde JJ et al (2015) Household electricity use, electric vehicle home-charging and distributed photovoltaic power production in the city of Westminster. Energy Build 86:439-448

[13] Junquera I (2014) Weather sation. https://www.facebook.com/ WSLaRevilla. Accessed 1 Jan 2014

[14] SmartV2G project (2012) Project objectives. Smart Vehicle to Grid Interface 284953:1-43

[15] NRG (2013) eV2g background. Lehigh University
[16] Stith P (2014) EV grid-vehicle grid integration services. Gridon-Wheels

[17] Stith P (2012) Grid-on-wheels project. Vehicle to Grid Demonstration

[18] Andersen PB, Olesen OJ, Poilasne G et al (2014) The Nikola project: intelligent electric vehicle integration. In: Proceedings of IEEE PES ISGT Europe, Istanbul, Turkey, 12-15 Oct 2014, 6 pp

[19] Nissan Motor Co. (2013) Nissan leaf can now power the office. 29 Nov 2013 Renault-Nissan Alliance Team

[20] Nissan Motor Co. (2012) Leaf to home electricity supply system with Nissan Leaf. LEAF to Home 2012.7.11 Nissan Motor Co., LTD

[21] What is the Smart Grid envisioned by Toyota? (2012) http:// www.toyota-global.com/innovation

[22] Sekisui house, toshiba and honda embody 2020 lifestyle of the future with real-world smart house. http://world.honda.com/ news/2014.html

[23] Castells FF (2015) Autoconsumo y vehículo eléctrico. Circutor, $1-60 \mathrm{pp}$

[24] García-Villalobos PJ, Zamora I, San Martín JI et al (2015) Delivering energy from PEV batteries: V2G, V2B and V2H approaches. In; Proceedings of International Conference Renewable Enegies and Power Quality, La Coruña, Spain, 25-27 Mar 2015, 6 pp

[25] BMW of North America (2015) BMWi chargedforward program

[26] Fattori F (2014) EVLS electric vehicles learning static model

[27] Fattori F, Anglani N, Muliere G (2014) Combining photovoltaic energy with electric vehicles, smart charging and vehicle-togrid. Solar Energy 110:438-451

[28] Smartgrid Gov (2011) Smart grid asset descriptions

[29] Adika CO, Wang L (2014) Autonomous appliance scheduling for household energy management. IEEE Trans Smart Grid 5(2):673-682

[30] Elnozahy MS, Salama MM (2014) Studying the feasibility of charging plug-in hybrid electric vehicles using photovoltaic electricity in residential distribution systems. Electr Power Syst Res 110:133-143

[31] Li X, Lopes LAC, Williamson SS (2009) On the suitability of plug-in hybrid electric vehicle (PHEV) charging infrastructures based on wind and solar energy. In: Proceedings of 2009 IEEE Power \& Energy Society General Meeting, Calgary, Canada, 26-30 July 2009, 8 pp

[32] Gurkaynak Y, Khaligh A (2009) Control and power management of a grid connected residential photovoltaic system with plug-in hybrid electric vehicle (PHEV) load. In: Proceedings of Applied Power Electronics Conference and Exposition, Washington, DC, USA, 15-19 Feb 2009, 6 pp

[33] Bedir A, Ozpineci B, Christian JE (2010) The impact of plug-in hybrid electric vehicle interaction with energy storage and solar panels on the grid for a zero energy house. In: Proceedings of Transmission and Distribution Conference and Exposition, New Orleans, LA, USA, 19-22 April 2010, 6 pp

[34] Marano V, Rizzoni G (2008) Energy and economic evaluation of PHEVs and their interaction with renewable energy sources and the power grid. In: Proceedins of IEEE International Conference on Vehicular Electronics and Safety, Columbus, OH, USA, 22-24 Sept 2008, 6 pp

[35] Aguero JR, Chongfuangprinya P, Shao S et al (2012) Integration of plug-in electric vehicles and distributed energy resources on power distribution systems. In: Proceedings of IEEE International Electric Vehicle Conference, Greenville, SC, USA, 4-8 March 2012, 7 pp

[36] Plug-in vehicle to home $(\mathrm{V} 2 \mathrm{H})$ duration and power output capability. http://www.utexas.edu/research/cem/RODEOPres/ TUTTLEPresentation.pdf. Accessed 22 Feb 2015 
[37] Pardo SA (2011) Generación distribuida Modelado de microeólica y solar. Generación Distrib. Model. micro-eólica y Sol., $1-17 \mathrm{pp}$

[38] Li XH, Hong SH (2014) User-expected price-based demand response algorithm for a home-to-grid system. Energy 64:437-449

[39] Zhao J, Kucuksari S, Mazhari E et al (2013) Integrated analysis of high-penetration PV and PHEV with energy storage and demand response. Appl Energy 112:35-51

[40] Rastegar M, Fotuhi-Firuzabad M, Aminifar F (2012) Load commitment in a smart home. Appl Energy 96:45-54

[41] Pipattanasomporn M, Kuzlu M, Rahman S (2012) An algorithm for intelligent home energy management and demand response analysis. IEEE Trans Smart Grid 3(4):2166-2173

[42] Kuzlu M, Pipattanasomporn M, Rahman S (2012) Hardware demonstration of a home energy management system for demand response applications. IEEE Trans Smart Grid 3(4):1704-1711

[43] Shao S, Pipattanasomporn M, Rahman S (2011) Demand response as a load shaping tool in an intelligent grid with electric vehicles. IEEE Trans Smart Grid 2(4):624-631

[44] Matallanas E, Castillo-Cagigal M, Gutiérrez A et al (2012) Neural network controller for active demand-side management with PV energy in the residential sector. Appl Energy 91(1):90-97

[45] Angelis FD, Boaro M, Fuselli D et al (2013) Optimal home energy managment under dynamic electrical and thermal constraints. IEEE Trans Ind Informatics 9(3):1518-1527

[46] Chen X, Wei T, Hu S (2013) Uncertainty-aware household appliance scheduling considering dynamic electricity pricing in smart home. IEEE Trans Smart Grid 4(2):932-941

[47] Missaoui R, Joumaa H, Ploix S et al (2014) Managing energy Smart homes according to energy prices: analysis of a building energy management system. Energy Build 71:155-167

[48] Tesla (2015) Powerwall- Tesla home battery. https://www.tesla. com/powerwall

[49] ISO 15118-1 (2013) road vehicles-vehicle to grid communication interface. International Organization for Standardization, 2013

[50] Wang Y, Sheikh O, Hu B et al (2014) Integration of V2H/V2G hybrid system for demand response in distribution network. In: Proceedings of IEEE International Conference on Smart Grid Communications (SmartGridComm), Venice, Italy, 3-6 Nov 2014, 6 pp

[51] Li D, Jayaweera SK (2014) Distributed smart-home decisionmaking in a hierarchical interactive smart grid architecture. IEEE Trans Parallel Distrib Syst 26(1):75-84

[52] Erdinc O, Paterakis NG, Mendes TDP et al (2014) Smart household operation considering bi-directional EV and ESS utilization by real-time pricing-based DR. IEEE Trans Smart Grid 6(3):1281-1291

[53] Wu Z, Zhou S, Li J et al (2014) Real-time scheduling of residential appliances via conditional risk-at-value. IEEE Trans Smart Grid 5(3):1282-1291
[54] Neubauer J, Wood E (2014) The impact of range anxiety and home, workplace, and public charging infrastructure on simulated battery electric vehicle lifetime utility. J Power Sources 257:12-20

[55] Zhou C, Qian K, Allan M et al (2011) Modeling of the cost of EV battery wear due to V2G application in power systems. IEEE Trans Energy Convers 26(4):1041-1050

[56] Speidel S, Bräunl T (2014) Driving and charging patterns of electric vehicles for energy usage. Renew Sustain Energy Rev 40:97-110

[57] García-Villalobos J, Zamora I, San Martín JI et al (2014) Plug-in electric vehicles in electric distribution networks: a review of smart charging approaches. Renewable and Sustainable Energy Reviews 38:717-731

[58] Schuller A, Dietz B, Flath CM et al (2014) Charging strategies for battery electric vehicles: economic benchmark and V2G potential. IEEE Trans Power Syst 29(5):2014-2022

Ibán JUNQUERA MARTÍNEZ received the Electrical Engineering degree and the Integration of Renewable Energy Sources into the Electric Power System master's degree from the University of the Basque Country, Spain, in 2013 and 2014. He is currently studying for the Ph.D. in Power Electric System of Electrical Engineering. His research interests include renewable energy sources, electric vehicles and distribution networks.

Javier GARCÍA-VILLALOBOS received the Automatic and Industrial Electronics Engineering degree and the Integration of Renewable Energy Sources into the Electric Power System master's degree from the University of the Basque Country, Spain, in 2010 and 2011, respectively. He is currently studying for the Ph.D. in Electrical Engineering. His research interests include electric vehicles, distribution networks and smart grids.

Inmaculada ZAMORA received her Electrical Engineering and $\mathrm{Ph} . \mathrm{D}$. degrees from the University of the Basque Country (Spain) in 1989 and 1993, respectively. She is currently a full time Professor in the Department of Electrical Engineering, University of the Basque Country. Her research interests include electric power systems, transients simulation, fault analysis, HVDC, micro generation and electrical vehicles.

Pablo EGUÍA received the M.Sc. and Ph.D. degrees in Electrical Engineering from the University of the Basque Country, Spain, in 1998 and 2007, respectively. He is currently Assistant Professor in the Department of Electrical Engineering at the University of the Basque Country. His research interests include power systems analysis, simulation and integration of distributed generation, and electrical vehicles. 